\title{
The Effects of Antioxidants Content on Mechanical Properties and Water Absorption Behaviour of Biocomposites Prepared by Single Screw Extrusion Process
}

\author{
Mohd Hafizuddin Ab Ghani, Mohd Nazry Salleh, Ruey Shan Chen, Sahrim Ahmad, \\ Mohd Rashid Yusof Hamid, Ismail Hanafi, and Nishata Royan Rajendran Royan
}

\begin{abstract}
Material Science Programme, School of Applied Physics, Faculty of Science and Technology, The National University of Malaysia, 43600 Bangi, Malaysia
\end{abstract}

Correspondence should be addressed to Mohd Hafizuddin Ab Ghani; mr_merce7@yahoo.com

Received 25 February 2014; Accepted 21 May 2014; Published 4 June 2014

Academic Editor: Yves Grohens

Copyright (C) 2014 Mohd Hafizuddin Ab Ghani et al. This is an open access article distributed under the Creative Commons Attribution License, which permits unrestricted use, distribution, and reproduction in any medium, provided the original work is properly cited.

\begin{abstract}
The performance of hybrid fillers between rice husk and sawdust filled recycled high density polyethylene (rHDPE) with the presence of antioxidants (IRGANOX 1010 and IRGAFOS 169, with the ratio of 1:1) was investigated. The biocomposites with $30 \mathrm{wt} \%$ of matrix and around $70 \mathrm{wt} \%$ of hybrid fillers (rice husk and sawdust) and different antioxidants' contents (0 to $0.7 \mathrm{wt} \%)$ were prepared with single screw extruder. Increasing the amount of antioxidants in biocomposites reduced the modulus of elasticity and modulus of rupture on flexural testing. The addition of antioxidants increased the tensile and impact strength of biocomposites. From the study, samples with $0.5 \mathrm{wt} \%$ of antioxidants produce the most reasonable strength and elasticity of biocomposites. Furthermore, the effect of antioxidants content on water uptake was minimal. This might be caused by the enhanced interfacial bonding between the polymer matrix and hybrid fillers, as shown from the morphology by using scanning electron microscopy (SEM).
\end{abstract}

\section{Introduction}

The large amount of disposable bottles presently produced makes the search for alternative procedures for recycling of these materials imperative. As chemical processing is most often costly and sometimes aggressive to the environment, a possible solution is the recycling of such material by thermomechanical techniques [1]. Great attention has been focused on the addition of natural fibres as reinforcement for plastics, replacing glass fibres and other synthetic materials. This is due to environmental concerns and also for providing a good combination of high performance, great versatility, and processing advantages at lower cost. Some drawbacks reduce the application of natural fibers as reinforcement in polymers, such as the incompatibility between fibres and polymer matrices, the tendency to form aggregates during processing, and the poor resistance to moisture. Incompatibility of components is responsible for poor thermal and mechanical properties. The stress transfer from the matrix to the fibre depends on fibre-fibre and fibre-matrix interactions [2].

To overcome this problem, it is necessary to promote polymer modification with polar groups (such as maleic anhydride or glycidyl methacrylate stearic acid) to enhance the adhesion between the composite components. The coupling agent more often used for this application is a polyethylene graft maleic anhydride (MAPE). Interactions between the anhydride groups of maleated coupling agents and the hydroxyl groups of natural fibres can overcome the incompatibility and increase tensile and flexural strengths of natural fibre thermoplastic composites [2].

In order to protect the biocomposites against thermooxidative degradation, antioxidants are used. In this study, two types of antioxidants, namely, IRGANOX 1010 (Pentaerythritol Tetrakis(3-(3,5-di-tert-butyl-4-hydroxyphenyl)propionate) and IRGAFOS 168 (Tris(2,4-di-tert-butylphenyl)phosphate), are used. IRGANOX 1010 is a sterically hindered 
phenolic antioxidant that is highly effective, nondiscoloring stabilizer for organic materials such as plastics, synthetic fibers, elastomers, adhesives, waxes, oils, and fats. This type of antioxidant can be applied in polyolefins, such as polyethylene, polypropylene, polybutene, and olefin copolymers such as ethylene-vinyl acetate copolymers. Also, its use is recommended in other polymers such as polyacetals, polyamides, and polyurethanes [3]. IRGAFOS 168 antioxidant is also known as a trisarylphosphite processing stabiliser. It is a highly effective, low-volatile, and hydrolysis resistant antioxidant for coating resins. It protects the resin polymer against oxidation during resin synthesis, manufacturing of the paint, processing (thermal curing and over baking), and the designed life time of the final coating. IRGAFOS 168 provides excellent protection against discoloration and change of physical properties caused by excessive heat exposure. In application, it provides outstanding thermal and color stability to a variety of coating resins upon exposure to high temperature during synthesis and subsequent processing [4].

Regarding economic and ecological factors, wood fibre plastic was established as a standard material, but unfortunately the price of raw wood fibre has increased by approximately $25-30 \%$ for the last two years and the sources are being limited. Therefore, new sources could be suitable alternatives for wood fibre. Grain byproducts, that is, rice husk and wheat husk, have sufficient fibre values, meaning that the proper utilization of waste materials will provide cheap engineering materials [5]. Recent interest in the environmental impact of polymer-based materials has led to the development of new products prepared with recycled polymers containing biodegradable materials. Lignocellulosic plastic composites constitute an important set within this kind of materials showing several advantages over traditional mineral-filled plastic composites such as low density, low production costs, biodegradability, and renewability. Hardness, stiffness, and dimensional stability of plastics have also been improved by incorporation of lignocellulosic fillers [6].

The combination of wood and plastics (thermoplastic) can produced an extrudable, injectable, or thermoformable composite. That new composite can be used in many applications especially in nonstructural industry. The wood industry can expand into new sustainable markets with the formation of a new class of composites with the combination of the wood industry and the plastics industry. The wood component, usually a flour or fiber, is combined with a thermoplastic to form an extrudable, injectable, or thermoformable composite that can be used in many nonstructural applications [7].

\section{Experimental}

2.1. Materials. The raw materials such as matrix and fillers were obtained from RePlas Sdn. Bhd. The matrix is recycled high density polyethylene (rHDPE). The fillers are mixed between sawdust ( 40 mesh) and rice husk ( 60 mesh) to create hybrid filler. And $3 \%$ of MAPE was added as a compatibilizer to improve the compatibility of hydrophobic polymer and hydrophilic hybrid fillers and thus improves the interfacial
TABLE 1: Formulation of biocomposite.

\begin{tabular}{lcccc}
\hline \multirow{2}{*}{ rHDPE (wt\%) } & \multicolumn{2}{c}{ Additives (wt\%) } & \multicolumn{2}{c}{ Fillers (wt\%) } \\
& Antioxidants & MAPE & Rice husk & Sawdust \\
\hline 30 & 0.0 & 3 & 45 & 22.0 \\
30 & 0.1 & 3 & 45 & 21.9 \\
30 & 0.3 & 3 & 45 & 21.7 \\
30 & 0.5 & 3 & 45 & 21.5 \\
30 & 0.7 & 3 & 45 & 21.3 \\
\hline
\end{tabular}

bonding between matrix and fillers as discussed by Rosa et al. [6]. The antioxidants (IRGANOX 1010 and IRGAFOS 168 as a ratio of $1: 1$ from Ciba) used in this study had been varied to examine their presence on mechanical properties and water absorption behavior. Five samples were produced according to the formulation in Table 1.

2.2. Processing. Rice husk was oven dried at $80^{\circ} \mathrm{C}$ for $24 \mathrm{~h}$ in order to reduce the moisture content to approximately $1-5 \%$ and then stored in sealed plastic bag before compounding. Biocomposites were processed in a single screw extruder (ULTRASLIT OHP 500) with an L/D ratio of 28. In all cases polymer matrix, fillers, antioxidants, and compatibilizing agent were fed together into the extruder hopper. The extrusion was conducted at temperature (from feed to die) of $160^{\circ} \mathrm{C}, 170^{\circ} \mathrm{C}, 170^{\circ} \mathrm{C}$, and $180^{\circ} \mathrm{C}$ with a screw speed of $70 \mathrm{rpm}$. The extruded strand was cooled at room temperature and pelletized.

WPC test specimens were produced using hot and cold press processes (LP50, LABTECH Engineering Company, LTD). Before hot and cold press processes, WPC pellets were ground using grinder to make it fine to suit with the mold. The ground pellets were then put in the mold size $14 \mathrm{~mm} \times$ $14 \mathrm{~mm} \times 3 \mathrm{~mm}$. The temperatures of the hot press were set $140^{\circ} \mathrm{C}$ for upper platen and lower platen, respectively. The period of preheating, venting, and full pressing were set at 3,2 , and 9 minutes, respectively. The cold press was set at 5 minutes to cool the specimens and the temperature used was $25^{\circ} \mathrm{C}$. The pressure used to press the specimens was set at $1000 \mathrm{psi}$ for both hot and cool press. After finishing the molding processes, the specimens had dried in oven for 24 hours with the temperature $70^{\circ} \mathrm{C}$ in order to remove any moisture left. The specimens were then cut according to ASTM specifications.

\subsection{Testing}

2.3.1. Tensile. The tensile tests were carried out in a universal testing machine (Testometric Universal) with cross head speed of $5 \mathrm{~mm} / \mathrm{min}$, according to ASTM D638-03 standard for Young's modulus and tensile strength values. Ten samples for each formulation are tested.

2.3.2. Flexural. The flexural tests were carried out following the ASTM D256-05 standard at room conditions using a universal testing machine (Testometric Universal) with a loading rate of $2.8 \mathrm{~mm} / \mathrm{min}$ for the modulus of rupture 
(MOR) and modulus of elasticity (MOE) values. Ten samples for each formulation are tested.

2.3.3. Impact. The impact test was carried out according to ASTM D 256-05 standard at room conditions using an Izod-Charpy (Ray-Ran) testing machine. The weight and velocity of the pendulum used were $0.452 \mathrm{~kg}$ and $3.46 \mathrm{~ms}^{-1}$, respectively. All the samples were notched on the center of one longitudinal side according to the ASTM D 256-05. For each treatment level, ten replications were tested. Ten samples for each formulation are tested.

2.3.4. Water Absorption. The water absorption test was performed following the ASTM D 570-98 standard. Water absorption was determined by the weight gain relative to the dry weight of the samples. Water absorption of the sample was recorded after $2 \mathrm{~h}, 12 \mathrm{~h}$, and $24 \mathrm{~h}$ until 2 months of immersion in distilled water at room temperature, $24^{\circ} \mathrm{C}$. Five specimens of each formulation were dried in an oven for $24 \mathrm{~h}$ at $80 \pm 2^{\circ} \mathrm{C}$. The dried specimens were weighed with precision of $0.001 \mathrm{~g}$. All specimens were immersed in distilled water. After reaching the time, specimens were removed from the distilled water, the surfaces of specimens were wiped off using tissue, and wet weight values were determined with the same precision $(0.001 \mathrm{~g})$. Water absorption $(M)$ percent was calculated using the following formula:

$$
M=\left[\frac{m_{t}-m_{o}}{m_{o}}\right] \times 100,
$$

where $m_{o}$ and $m_{t}$ represent the oven-dry weight and weight after time $t$, respectively. The same method was applied to study water absorption of biocomposites by using sea water.

2.3.5. Morphology. The scanning electron microscopy (SEM) was used to evaluate the fractured surface of the biocomposites. The microscope was operated at a voltage of $15 \mathrm{kV}$. The surface was sputtered with a thin gold layer.

\section{Results and Discussion}

3.1. Tensile Test. Figures 1 and 2 represent graph of tensile strength and Young's modulus, respectively. From the results of Figure 1, it is shown that samples with antioxidants content have higher result compared to control sample (without antioxidants content). As can be seen from the graph, sample with $0.5 \mathrm{wt} \%$ of antioxidants gives the highest value which is $8.1 \mathrm{MPa}, 11 \%$ higher than control sample. The tensile strength markedly increased with increasing antioxidants content by creating good interfacial bonding between the hydrophobic matrix polymer hydrophilic filler and coupling agent. The sufficient amount of antioxidants content can increase the tensile strength of biocomposites [7], while Chong et al. [8] explain that the decrement of tensile strength on biocomposites is due to the weak bonding between the matrix and filler. In addition, filler agglomerations also lead to uneven dispersion in matrix, thus weakening the tensile strength of the material.

Graph of Young's modulus shows decrement trend from control sample to $0.7 \mathrm{wt} \%$ antioxidants content. The highest

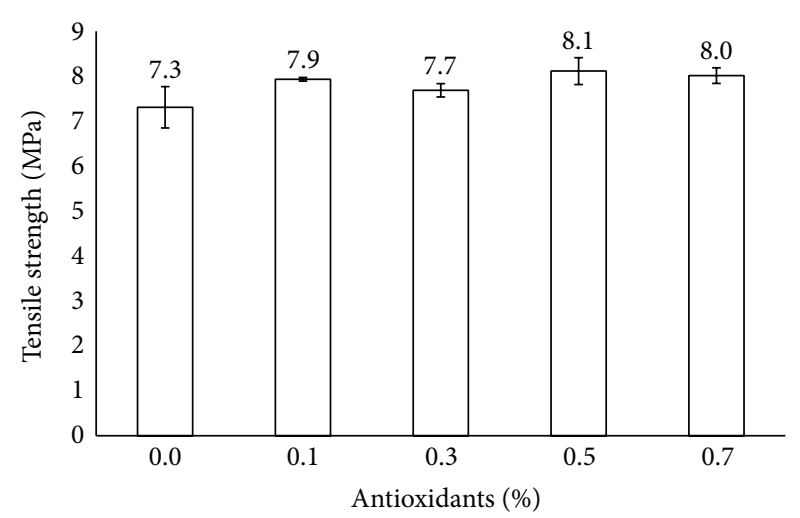

FIgURE 1: Tensile strength.

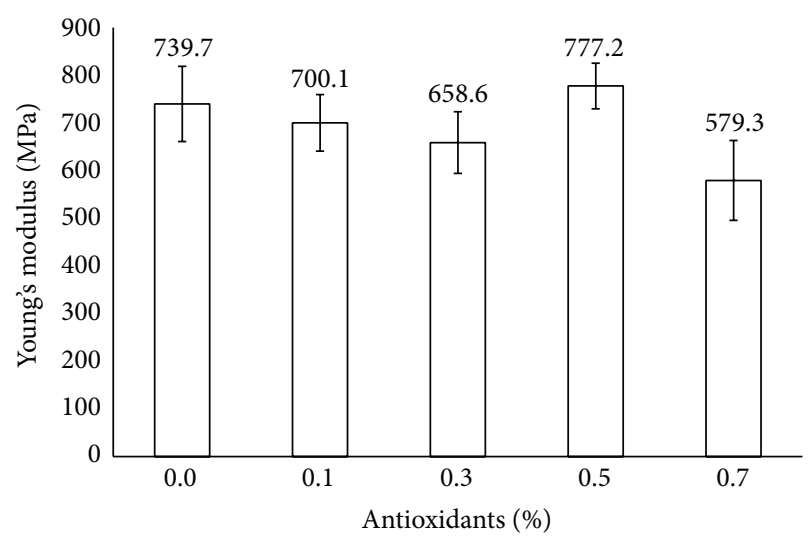

FIGURE 2: Young's modulus.

and lowest values are 777.2 MPa and 579.3 MPa recorded from $0.5 \mathrm{wt} \%$ and $0.7 \mathrm{wt} \%$ antioxidants' contents, respectively. Sample with $0.5 \mathrm{wt} \%$ antioxidants content gives unexpected increment maybe due to contaminants in the sample. The composites produced by using recycled plastics should expect contamination effect in matrix that can be one of the drawbacks in this field [7].

3.2. Flexural Test. Figures 3 and 4 illustrate the modulus of elasticity (MOE) and modulus of rupture (MOR), respectively. The results show the trend that addition of antioxidants reduces the values of MOE and MOR. These results were in contradiction with our previous study [9]. Our last study showed that the values of MOR and MOE were increased by increment amount of antioxidants content. These differentiations can be explained by using different types of extruder machine that will give the different flexural testing values.

Graph modulus of elasticity shows the decrement trend from control sample to sample with content of $0.5 \mathrm{wt} \%$ of antioxidants. There is slight increment value shown by sample content of $0.7 \mathrm{wt} \%$ of antioxidants. The control sample gives strength of $2548.5 \mathrm{MPa}$, while sample with $0.1 \mathrm{wt} \%$ antioxidants content has $2302.8 \mathrm{MPa}$. This value shows the highest reading among all the five samples tested. The lowest 


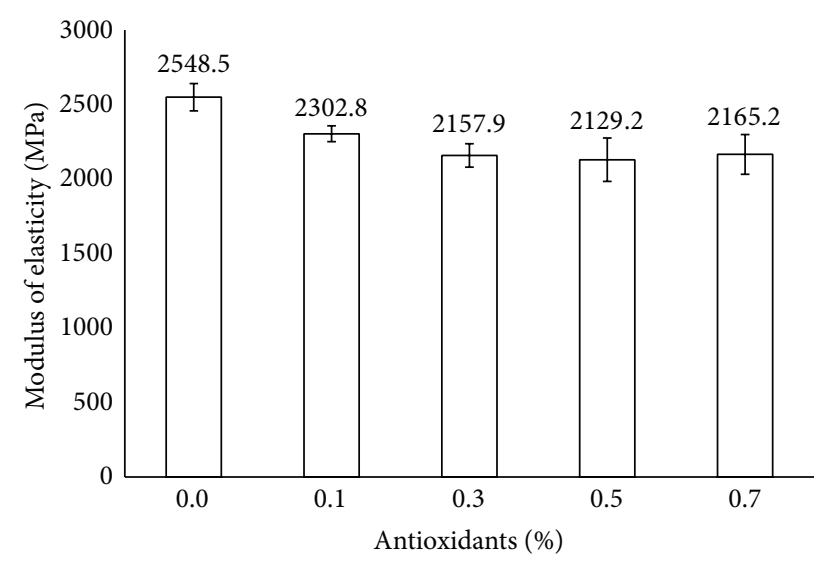

Figure 3: Modulus of elasticity.

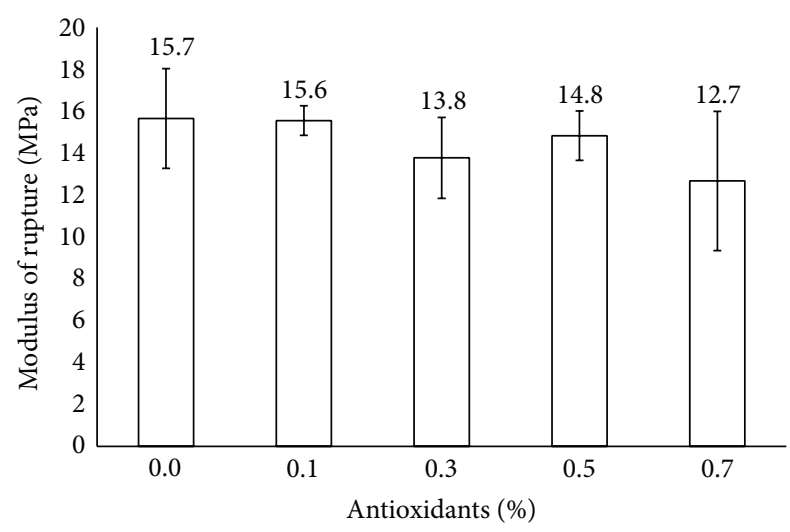

FIgUre 4: Modulus of rupture.

MOE reading was recorded by sample content of $0.5 \mathrm{wt} \%$ of antioxidants which is $2129.2 \mathrm{MPa}$. Percentage differentiation between the highest and the lowest values of MOE is approximately $17 \%$.

Mixing recycled high density polyethylene as a matrix, wood powder as filler, and coupling agent with a mixture ratio of $47: 50: 3$ gives MOE value equal to or higher than biocomposites produced by using virgin plastic. In addition, this type of mixture can produce strong, stable composites and can be used as building materials [10]. According to Chen et al. [11], MOE of composites increased with increasing amount of wood particles content up to $60 \mathrm{wt} \%$. However, if more than $60 \mathrm{wt} \%$ of wood particles mix in sample this will weaken the mechanical properties of the composite.

The modulus of rupture also shows the decrement trend on plotted graph. The control sample recorded the highest value for MOR which is $15.7 \mathrm{MPa}$. Sample containing $0.1 \mathrm{wt} \%$ of antioxidants decreased $0.6 \%$ of control sample value and recorded 15.6 MPa for MOR. Sample with $0.3 \mathrm{wt} \%$ antioxidants content reduces by $12 \%$ compared to control sample and gives the MOR value of $13.8 \mathrm{MPa}$. Another two samples, namely, $0.5 \mathrm{wt} \%$ and $0.7 \mathrm{wt} \%$, of antioxidants content give 14.8 $\mathrm{MPa}$ and $12.7 \mathrm{MPa}$, respectively, for MOR. These two

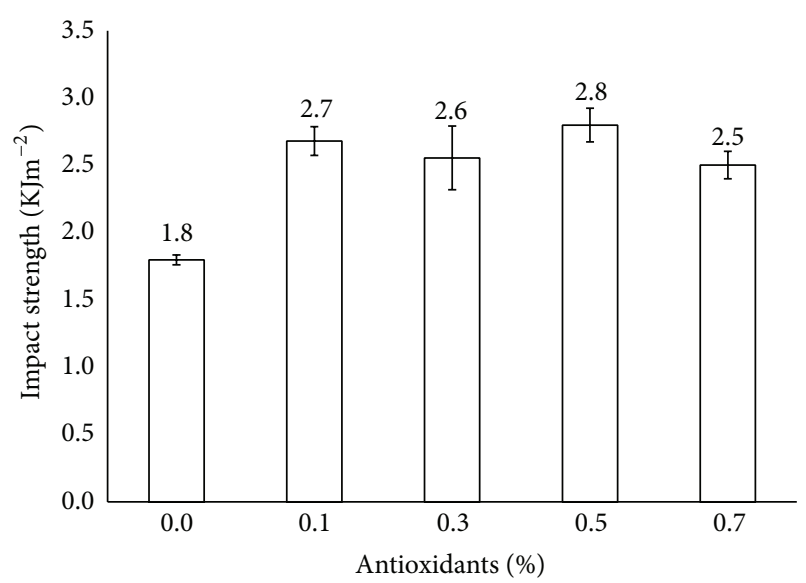

FIGURE 5: Impact strength.

values show the decreasing trend as much as $5 \%$ and $19 \%$ from control sample, respectively.

The presence of antioxidants prevents free radical atom from diffusing in biocomposites, while the density of material acts as a gatekeeper to control the number of oxygen molecules penetrating into the matrix. Thus, production of high density biocomposites can reduce the existence of excess oxygen molecules in composite material. A small amount of oxygen molecules in biocomposites will reduce the oxidative degradation process and consequently decrease the flexural values [7].

3.3. Impact Test. Figure 5 shows the impact strength graph. The graph has an increment trend from control sample to the fifth sample with the content of $0.7 \mathrm{wt} \%$ of antioxidants. Although there is a slight decrement shown from sample with the content of $0.3 \mathrm{wt} \%$ of antioxidants, this result is still higher compared to the control sample.

From the graph, the control sample gives the value $1.8 \mathrm{KJm}^{-2}$ which is $36 \%$ less than the highest value recorded from sample with the content of $0.5 \mathrm{wt} \%$ antioxidants. The highest value for impact testing is $2.8 \mathrm{KJm}^{-2}$ as plotted in the graph above. This result could be explained by chemical composition of fiber that had been used. Wood fiber contains high cellulose and hemicellulose; these two types of cell are hydrophilic. Any moisture penetrated into samples while processing or assembling will affect the values of testing. Besides that, poor adhesion between matrix and hybrid fibers generates void spaces at interfacial of polymer-filler. These lead to lower impact strength of the samples [7].

3.4. Water Absorption Test. Figures 6 and 7 show graph of the water absorption for samples immersed in two types of water, namely, distilled and sea water, respectively. From the graphs, both show the same increment trend until reaching the optimum water absorption of samples. In this study, the amounts of antioxidants added could affect the bonding between the matrix and fibres. Addition of antioxidants helped in decreasing the water uptake of the biocomposites. This is because the antioxidants as mineral fillers have distributed 


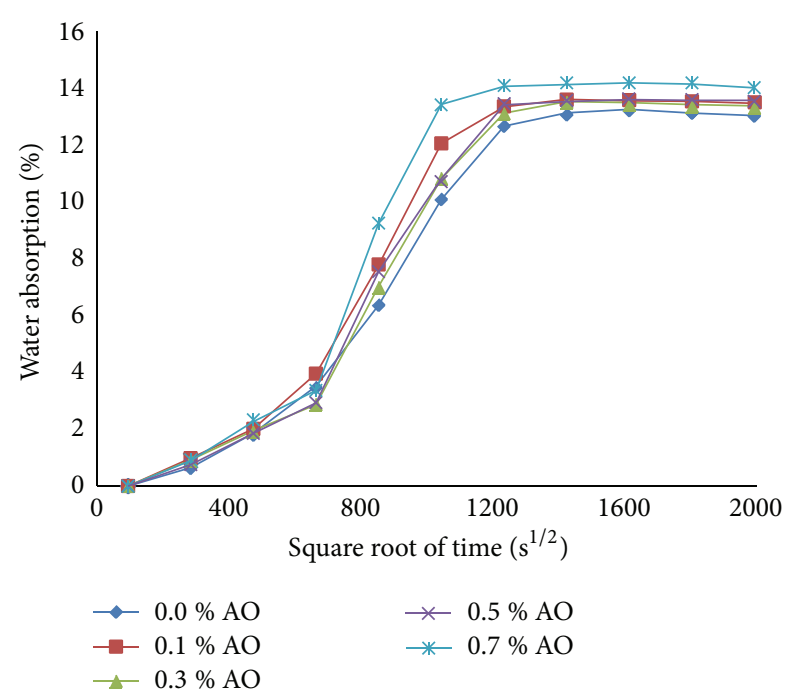

FIGURE 6: Distilled water.

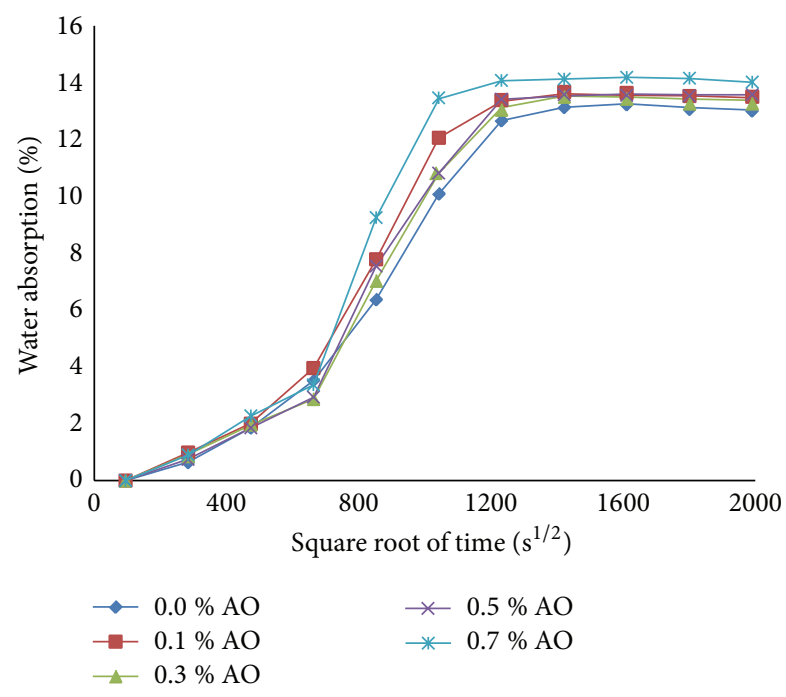

Figure 7: Sea water.

and penetrated well into the fibres, which prevents water from entering the samples. The water uptake increases substantially with increasing fibre content. According to Klyosov [7], the water absorption for biocomposites is typically $0.7-2 \%$ after 24 hours and $1-5 \%$ after a week and increases to $18-22 \%$ after several months of submersion in water.

This result could be explained by the wood chemical composition. Organic fibre especially sawdust contains high hydrophilic content. Celluloses and hemicelluloses are the main cause for the high water absorption of natural fibres. This is because they contain hydroxyl groups. Besides that, poor wettability between fibre particles and the polymer matrix generates void spaces around the fibre particles. Because of poor wetting, the filler particles create hollow spaces, introducing porosity to the internal structure of the biocomposites as indicated in Figure 8. Dewetting of the polymer at the interphase creates stress concentration points.

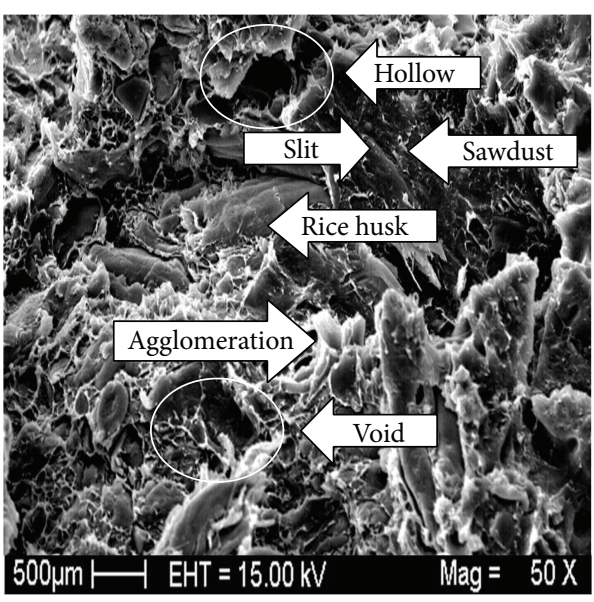

FIGURE 8: With $0.0 \mathrm{wt} \%$ antioxidants content.

These lead to higher water uptake in the composites natural fibre base.

According to Panthapulakkal and Sain study [12], the absorption of water on thermoplastic composite reinforced natural fibre mainly caused by microcracks that form on the surface and also in the material. Besides that, swelling fiber caused by water or moisture while producing the samples can also affect the water absorption rate. They also stressed on disconnection bond between matrix and filler due to high ambient temperature contributing to the absorption of water in tested samples.

The absorption of water in composite increased proportionally with the time of immersion until reaching the saturation point. Water absorption rate is higher in sea water compared to distilled water. This is caused by the presence of metal ions such as $\mathrm{Na}^{+}, \mathrm{K}^{+}, \mathrm{Ca}^{++}$, and $\mathrm{Mg}^{++}$in sea water [13]. The finding was supported by Silva et al. [14]; the sedimentation of metal ions was formed on the filler in reinforced thermoplastic composite. Therefore, it can be concluded that high amounts of metal ions of sea water will form sediment in the container. The sediment formed due to chemical reaction between metal ions and biocomposites. As a result, it will affect the rate of water absorption and thus deteriorate the mechanical properties of the material.

3.5. Morphology Test. Figures 8 and 9 show the results of scanning electron microscopy (SEM) morphology for samples without antioxidants and with $0.5 \mathrm{wt} \%$ antioxidants content, respectively. Sample without antioxidants content shows the agglomeration of fibers. The agglomeration is formed due to uneven distribution of fibers during extrusion and compression processes. The agglomeration of materials can affect the mechanical and physical properties of biocomposites. A slit is seen through the sawdust fiber; this could be explained by stress transfer from the matrix to the filler. The stress-strain process occurred from weaker part to stronger part. In this biocomposites, the recycled high density polyethylene matrix is weaker than hybrid fillers.

In Figure 9 image, there is no clear cleft that can be seen between matrix and fibers; this situation indicates 


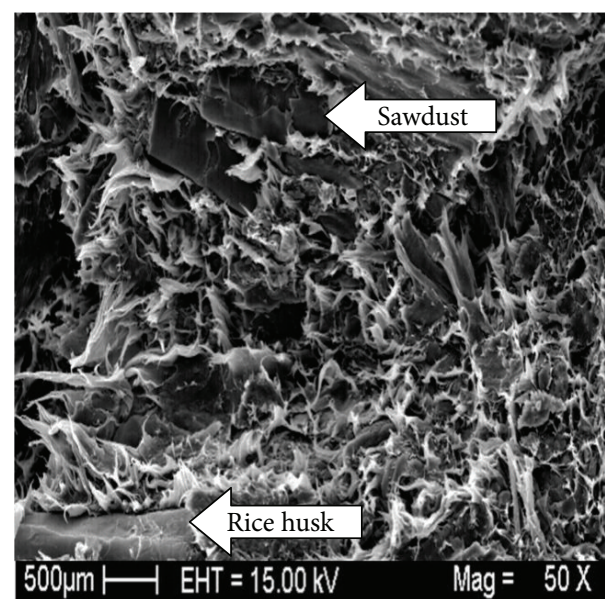

Figure 9: With $0.5 \mathrm{wt} \%$ antioxidants content.

the good interface bonding between them. In addition, the morphology shows that the fibres were utterly attached to the matrix and it is also evident that the fibres were strongly imbedded in the matrix, indicating the efficiency of the mixing, which was attributed to a good interfacial interaction between hybrid fibres and matrix [15]. The interfacial bonding was improved due to the esterification mechanism, and the fracture occurred at the fibres themselves. This means that the stress is well propagated between the fibres/fillers and the matrix polymer, resulting in enhanced tensile strength and modulus in response to stress [10].

\section{Conclusion}

Antioxidants were proven to be effective in increasing the mechanical properties and water absorption of the biocomposites. This indicates that the addition of antioxidants as additive improves the properties and the durability performance of recycled high density polyethylene reinforced with a hybrid of rice husks and sawdust. Besides the addition of antioxidants, there are various parameters influencing the mechanical properties of fibre-reinforced composites including the stress transfer at the interface, fibre aspect ratio, mixing temperatures, addition of a coupling agent, and the fibre-matrix adhesion. In conclusion, the mechanical properties of the biocomposites significantly increased with the addition of antioxidants content except for flexural test. The increment of antioxidants content reduced the modulus of elasticity and modulus of rupture.

\section{Conflict of Interests}

The authors declare that there is no conflict of interests regarding the publication of this paper.

\section{References}

[1] A. F. Ávila and M. V. Duarte, "A mechanical analysis on recycled PET/HDPE composites," Polymer Degradation and Stability, vol. 80, no. 2, pp. 373-382, 2003.
[2] J. R. Araújo, W. R. Waldman, and M. A. de Paoli, “Thermal properties of high density polyethylene composites with natural fibres: coupling agent effect," Polymer Degradation and Stability, vol. 93, no. 10, pp. 1770-1775, 2008.

[3] S. C. Ciba, Irganox 1010 Phenolic Primary Antioxidant for Processing and Long-Term Thermal Stabilization, Ciba Specialty Chemicals, 1998.

[4] S. C. Ciba, Irgafos 168, Processing Stabiliser, Ciba Specialty Chemicals, 2005.

[5] A. K. Bledzki, A. A. Mamun, N. N. Bonnia, and S. Ahmad, "Basic properties of grain by-products and their viability in polypropylene composites," Industrial Crops and Products, vol. 37, no. 1, pp. 427-434, 2012.

[6] S. M. L. Rosa, E. F. Santos, C. A. Ferreira, and S. M. B. Nachtigalt, "Studies on the properties of rice-husk-filled-PP compositeseffect of maleated PP," Materials Research, vol. 12, no. 3, pp. 333338, 2009.

[7] A. A. Klyosov, Plastic Composites, John Wiley \& Sons, New York, NY, USA, 2007.

[8] E. L. Chong, I. Ahmad, H. M. Dahlan, and I. Abdullah, "Reinforcement of natural rubber/high density polyethylene blends with electron beam irradiated liquid natural rubbercoated rice husk," Radiation Physics and Chemistry, vol. 79, no. 8, pp. 906-911, 2010.

[9] M. H. Ab Ghani and S. Ahmad, "Effects of antioxidants content on the physical and mechanical properties of wood plastic composites," Key Engineering Materials, vol. 471-472, pp. 151156, 2011.

[10] K. B. Adhikary, S. Pang, and M. P. Staiger, "Dimensional stability and mechanical behaviour of wood-plastic composites based on recycled and virgin high-density polyethylene (HDPE)," Composites B: Engineering, vol. 39, no. 5, pp. 807-815, 2008.

[11] H. C. Chen, T. Y. Chen, and C. H. Hsu, "Effects of wood particle size and mixing ratios of HDPE on the properties of the composites," European Journal of Wood and Wood Products, vol. 64, no. 3, pp. 172-177, 2006.

[12] S. Panthapulakkal and M. Sain, "Agro-residue reinforced highdensity polyethylene composites: fiber characterization and analysis of composite properties," Composites A: Applied Science and Manufacturing, vol. 38, no. 6, pp. 1445-1454, 2007.

[13] S. K. Najafi and H. Y. Kordkheili, "Effect of sea water on water absorption and flexural properties of wood-polypropylene composites," European Journal of Wood and Wood Products, vol. 69, no. 4, pp. 553-556, 2011.

[14] R. V. Silva, E. M. F. Aquino, L. P. S. Rodrigues, and A. R. F. Barros, "Curaua/glass hybrid composite: the effect of water aging on the mechanical properties," Journal of Reinforced Plastics and Composites, vol. 28, no. 15, pp. 1857-1868, 2009.

[15] M. R. Y. Hamid, M. H. Ab Ghani, and S. Ahmad, "Effect of antioxidants and fire retardants as mineral fillers on the physical and mechanical properties of high loading hybrid biocomposites reinforced with rice husks and sawdust," Industrial Crops and Products, vol. 40, no. 1, pp. 96-102, 2012. 

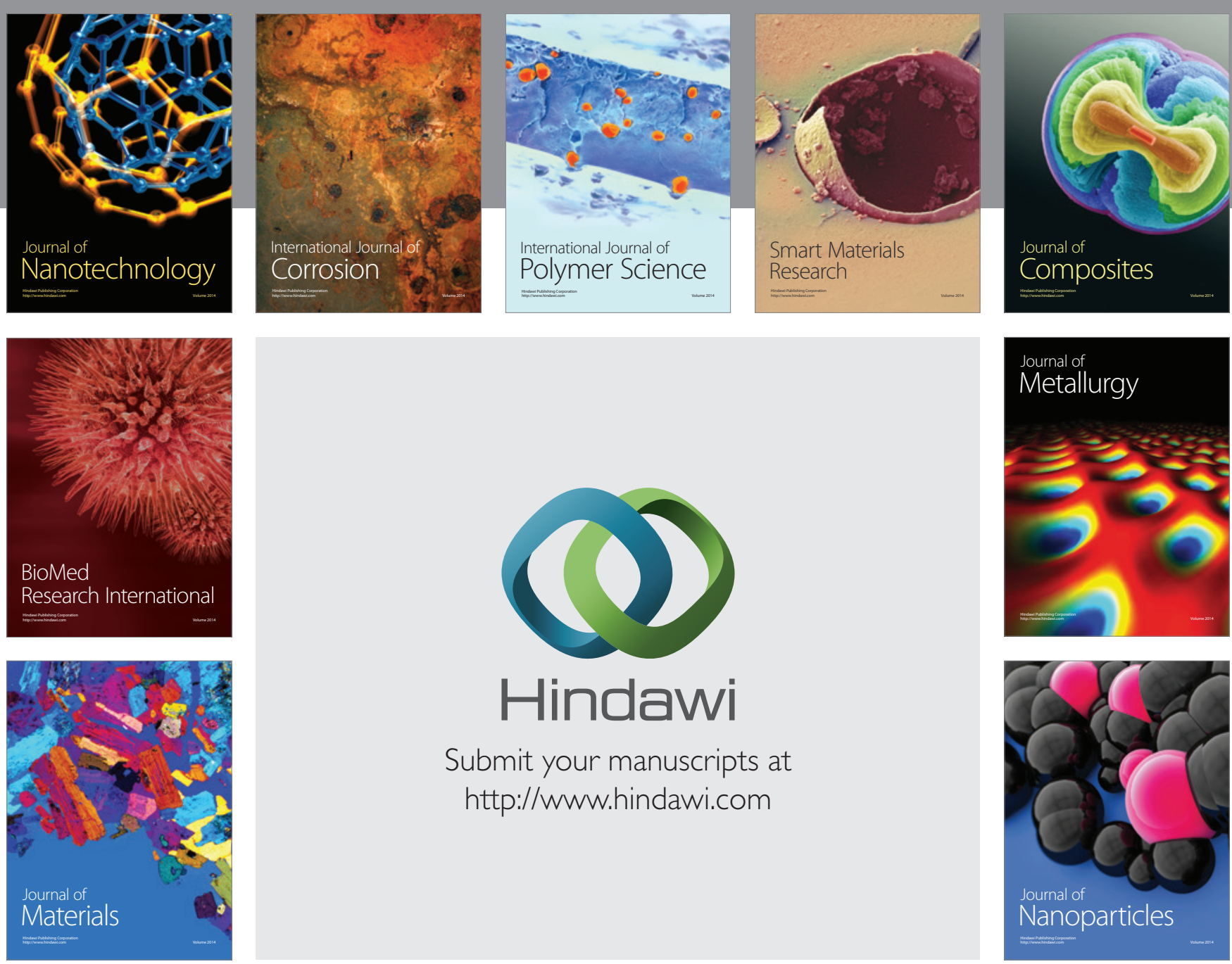

Submit your manuscripts at http://www.hindawi.com
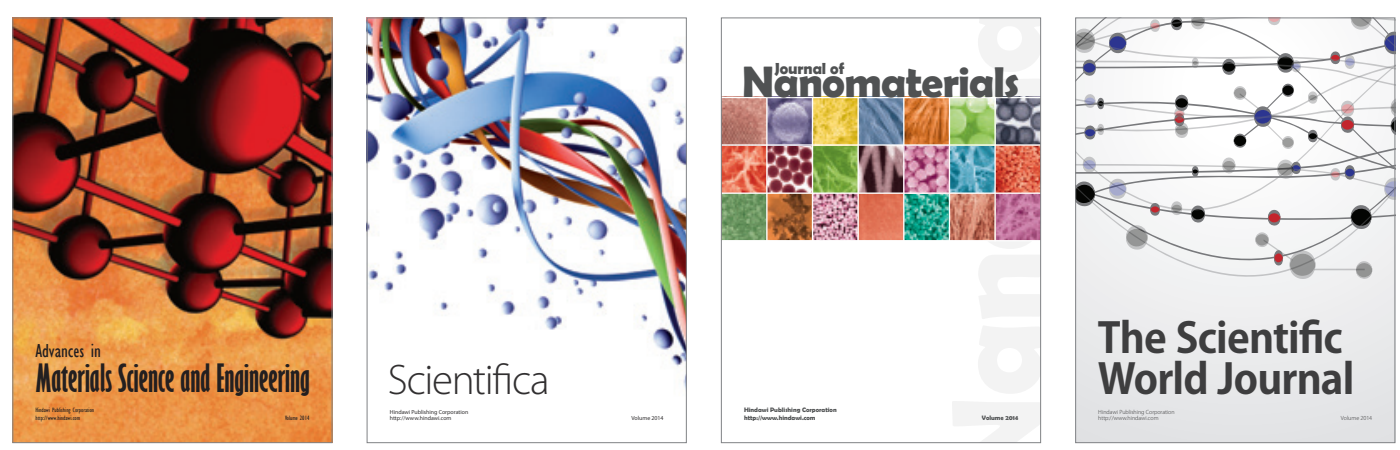

\section{The Scientific World Journal}
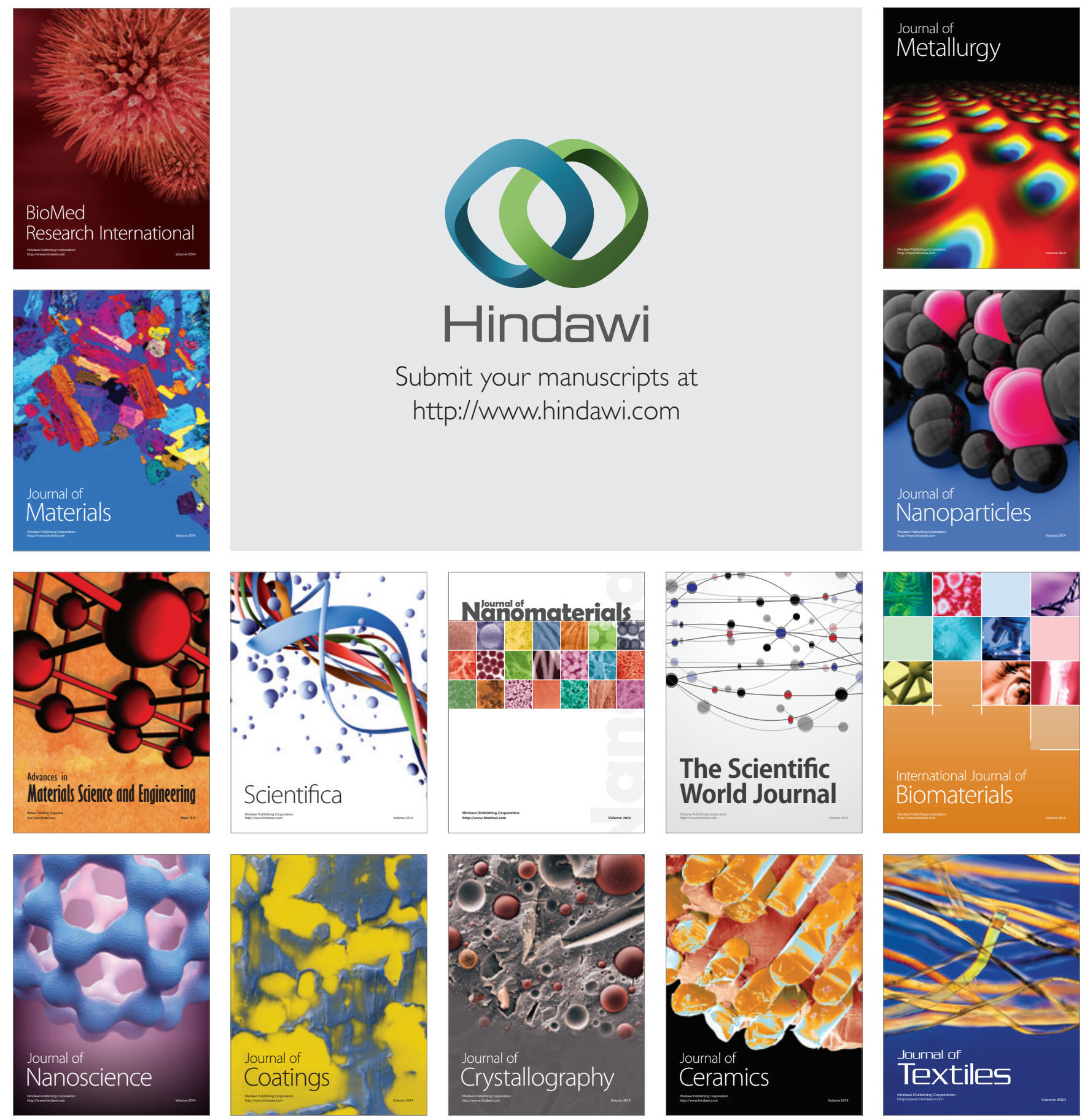